\title{
Green Mediated Synthesis and Characterization of ZnO Using Euphorbia Milli Latex as Fuel
}

\author{
Geetha .M .S ${ }^{1}$, Nagabhushana.$H^{2}$, Shivananjaiah $. H ~ . \mathbf{N}^{3}$ \\ ${ }^{1}$ Vijaya composite college, Jayanagar, Bengaluru 560 011, India \\ ${ }^{2}$ CNR Rao centre for Advanced materials, Tumkur University, Tumkur 572 103, India \\ ${ }^{3}$ Government science college, Bangalore University, Nrupatunga Road, Bengaluru 560 001, India
}

\begin{abstract}
In this paper, a simple green route combustion method of synthesis was adopted for the synthesis of Zinc oxide nano particles using Euphorbia milli latex as fuel. As prepared product was characterized by Powder X Ray Diffractometer (PXRD), Fourier Transform Infra-Red spectroscopy (FTIR), UV-Visible spectroscopy, Rietveld refinement, Scanning Electron Microscopy - Energy Dispersive Spectroscopy (SEM-EDS) and Transmission Electron Microscopy (TEM). The concentration of plant extract plays an important role in controlling the size of the particle and its morphology. PXRD graphs showed that the particles were well crystallised. The average particle size was calculated using Scherrer equation and advanced WH plots. The average particle size is around 50nm. This result was also supported by SEM and TEM analysis. FTIR shows the characteristic peak of ZnO at $435 \mathrm{~cm}^{-1}$. SEM and TEM micro graphs show that the particles are spherical in nature. EDS of SEM analysis confirmed that the elements are only Zn and $O$. No other impurity elements were found in the sample. Crystal parameters were determined using Rietveld refinement. From UV-Visible spectra band gap energy was found to be $3.44 \mathrm{eV}$. This method is fast, eco friendly and convenient for the synthesis of ZnO nano particles (NPs).
\end{abstract}

Keywords: ZnO NPs, Euphorbia milli latex, SEM with EDS, Rietveld refinement

\section{Introduction}

Nano crystalline metal oxides have attracted wide attention due to their unique properties, which are technologically very useful in nano device fabrications. In recent years, nanomaterials have been widely studied compared to their bulk materials due to their interesting chemical and physical properties [1]. Among them, Zinc oxide is a unique and very important inorganic material. This is because of its distinct characteristic features and novel applications in wide areas of technology and science. ZnO has typical properties such as transparency in the visible range, direct band gap, high electrochemical stability, toxic absorbance and plenty of availability in nature [2]. The III-V and II-VI based dilute magnetic semiconductors (DMS) are very encouraging materials for spintronics applications because DMS show ferromagnetic nature at room temperature [3]. $\mathrm{ZnO}$ has a high excitation binding energy of $60 \mathrm{meV}$ and wide semiconductor band gap of $\sim 3.37 \mathrm{eV}[4,5]$. It is one of the hardest materials in the II to VI group of elements. As a result of this $\mathrm{ZnO}$ devices do not suffer from dislocation degradation during working [6-8]. ZnO has gained much importance as it can be applied in many applications such as for gas sensing, catalyst, for semiconductors, UV-shielding materials, nano generators, an antibacterial agent, cosmetics as well as medicinal applications [9-13]. In recent days controllable synthesis of $\mathrm{ZnO}$ nanomaterials of desired size and shapes has been the subject of investigation by researchers because it has been found that most of the properties of $\mathrm{ZnO}$ nanoparticles are size and morphology dependent. Several methods have been developed to synthesize $\mathrm{ZnO}$ nanoparticles such as precipitation, hydrothermal, combustion, sono chemicals, chemical vapor deposition, spray pyrolysis, sol gel [14-20]. Among various methods developed, combustion synthesis is a simple, convenient, fast and efficient method which involves the redox reaction between an oxidizing reagent usually desired metal salts and a reducing agent forming highly pure products [21,22].

Euphorbia milli is a species of flowering plant in the spurge family, Euphorbia, native to Madagascar. The sap is moderately poisonous and causes irritation on contact with skin or eyes. This plant has gained the Royal Horticultural Society's Award of Garden Merit. Euphorbia milli serves as a potted ornamental in many different countries. Tropical residents also use it for hedges. Euphorbia milli plays a role in folk medicine. The Chinese use it as a cure for cancer, and some Brazilians believe that it can cure warts. Milin, an extract of Euphorbia milli latex, is a glycosylated serine protease (an enzyme that breaks down protein and has a sugar attached to it). Because it is more stable than most proteases, it will be useful to food processers and makers of detergents who have been using proteases in their operations. Milin will also be useful to research scientists who use serine proteases to get rid of unwanted proteins so that they can obtain the ones they want in pure form.

Green mediated synthesis was largely unexploited compared to other synthesis routes. Chandrasekhar et al. [23] reported the synthesis of $\mathrm{ZnO}$ :Eu3+ nano phosphor using E-tirucalli plant latex. The phosphors synthesized by this method showed very good chromaticity coordinates in the white light region which was highly useful for white light emitting diodes. D. Kavyashree et al synthesised $\mathrm{ZnO}$ using Guizotia abyssinica seed extract and reported that the prepared samples can be used for the display device applications[24]. D. Suresh et al. studied Photo degradative, antimicrobial and 


\section{International Journal of Science and Research (IJSR) \\ ISSN (Online): 2319-7064 \\ Index Copernicus Value (2013): 6.14 | Impact Factor (2015): 6.391}

antioxidant activities of $\mathrm{ZnO}$ nano powders and reported that $\mathrm{ZnO}$ can be a good photo degradative [25].

\section{Experimental}

In the present report, the milky latex of Euphorbia milli was used as a reducing agent for the synthesis of Zinc oxide (ZnO) nano particles. Hydrated Zinc Nitrate was procured from Sigma-Aldrich and used as starting materials without further purification. Latex of Euphorbia milli was used as fuel for synthesis of $\mathrm{ZnO}$ nano particles. In a typical synthesis $2 \mathrm{ml}, 4 \mathrm{ml}$ and $6 \mathrm{ml}$ of crude latex were dissolved in 8ml-10 $\mathrm{ml}$ of double distilled water. To each $1 \mathrm{~g}$ of Zinc Nitrate was added and mixed well using magnetic stirrer for approximately 5-10 min and then placed in a preheated muffle furnace maintained at $450 \pm 10^{\circ} \mathrm{C}$. The reaction mixture boils froths and thermally dehydrates forming foam. The entire process was completed in less than $30 \mathrm{~min}$. Further, the final white powder was kept for calcination at a temperature of $750{ }^{\circ} \mathrm{C}$ for two hr in the muffle furnace.

\section{Results and Discussion}

Fig. 1 shows the PXRD pattern of ZnO NPs prepared using different volumes of E.milli latex (2ml, $4 \mathrm{ml}, 6 \mathrm{ml})$ fuel via solution combustion method. All the diffraction peaks were indexed to hexagonal wurtzite structure of $\mathrm{ZnO}$ NPs with lattice constants $\mathrm{a}=3.2595 \AA$, c $=5.221 \AA$.

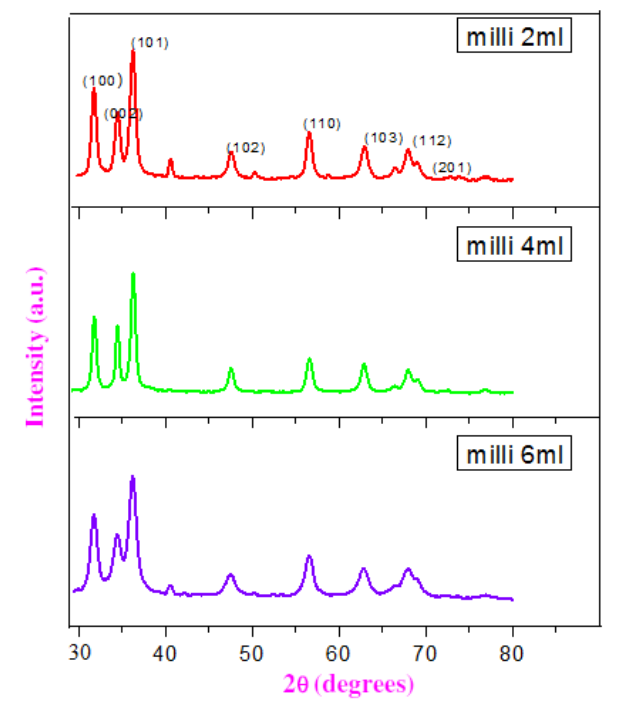

Figure 1: PXRD patterns of $\mathrm{ZnO}$ prepared using latex of Euphorbia milli as fuel (2ml, $4 \mathrm{ml}$ and $6 \mathrm{ml})$.

The crystallite size of the ZnO NPs with different E.milli latex was calculated using Scherrer's equation $D=k \lambda / \beta \cos \theta$ where $\mathrm{D}$ is the crystal size, $\mathrm{k}$ is the shape constant $(\sim 0.9), \lambda$ is the $X$ ray wavelength, $\theta$ is the Bragg's angle and $\beta$ is the line broadening at half the maximum intensity (FWHM) in radians. The crystallite size was found to be in the range of 3-11 nm. Further dislocation density $(\delta)$ and micro strain $(\epsilon)$ was estimated by the relation $\delta=1 / \mathrm{D}^{2}$ where $\mathrm{D}$ is the crystal size in $\mathrm{nm}$ and micro strain $\varepsilon=\beta \cos \theta / 4$. The micro strain is found to increase with increase in fuel concentration. The average dislocation density for $6 \mathrm{ml}, 4 \mathrm{ml}$ and $2 \mathrm{ml}$ E.milli was found to be $104.49 \times 10^{15}, 59.53 \times 10^{15}$ and $24.38 \times 10^{15}$ as shown in Table1.The small $\delta$ for ZnO NPs indicates higher crystallization of the sample. Thus $6 \mathrm{ml}$ shows high level of surface defects and deteriorates crystal quality. But $4 \mathrm{ml}$ and $2 \mathrm{ml} \mathrm{ZnO} \mathrm{NPs} \mathrm{shows} \mathrm{the} \mathrm{low} \mathrm{level} \mathrm{of} \mathrm{surface} \mathrm{defects.}$

Table 1: Crystallite size, strain, Dislocation density and stress of $\mathrm{ZnO}$ nano particles prepared by various concentration of E. milli plant milky latex

\begin{tabular}{|c|c|c|c|c|}
\hline $\begin{array}{c}\text { Sample } \\
\mathrm{ZnO} \\
(\mathrm{ml})\end{array}$ & $\begin{array}{c}\text { Scherrer } \\
\text { Equation } \\
\mathrm{D}(\mathrm{nm})\end{array}$ & $\begin{array}{c}\text { Strain } \\
\varepsilon \times 10^{-3}\end{array}$ & $\begin{array}{c}\text { Dislocation } \\
\text { density } \delta=1 / \mathrm{D}^{2} \\
\times 10^{15}\end{array}$ & $\begin{array}{c}\text { Stress } \\
\zeta=\varepsilon Y \times 10^{6} \mathrm{Nm}^{-2}\end{array}$ \\
\hline 2 & 11 & 4.68 & 24.338 & 0.609 \\
\hline 4 & 5 & 7.77 & 59.536 & 1.01 \\
\hline 6 & 3 & 10.94 & 104.494 & 1.422 \\
\hline
\end{tabular}

The crystallite size was also estimated for the powder from the full width half maximum of the diffraction peaks using William Hall modified form strain, Uniform Deformation Model (UDM), Uniform Stress Deformation Model (USDM), Uniform Deformation Energy-Density Model (UDEDM). Depending on different $\theta$ positions the separation of size and strain broadening analysis was done using William and Hall plots. The following results are the addition of the Scherrer equation and $\varepsilon \approx \beta \mathrm{s} / \tan \theta$. Therefore $\beta_{\mathrm{hkl}}=(\mathrm{k} \lambda / \beta \cos \theta)+4 \epsilon \tan \theta$. Rearranging this equation we get $\beta \cos \theta=k \lambda / D+4 \varepsilon \sin \theta$.This equation stands for Uniform Deformation Model (UDM), where it is assumed that strain is uniform in all crystallographic directions. From the lattice parameters calculations it was observed that this strain might be due to the lattice shrinkage. Figure 2 shows $\mathrm{W}-\mathrm{H}$ plot (UDM) of $\mathrm{ZnO}$ nanoparticles using E.millii latex as fuel.

Using the intercept and slope, particle size and micro strain were calculated.UDM analysis is shown in Table2.From the Hooke's Law maintaining linear proportionality between stress and strain, $\zeta=Y \varepsilon$, where $\zeta$ is the stress and $Y$ is the Young's modulus. USDM was a plot of $\beta \cos \theta$ versus $4 \sin \theta$ $/ \mathrm{Y}$ (where $\mathrm{Y}=130 \times 10^{9} \mathrm{Nm}^{-2}$ ) The USDM plot was shown in figure 3.

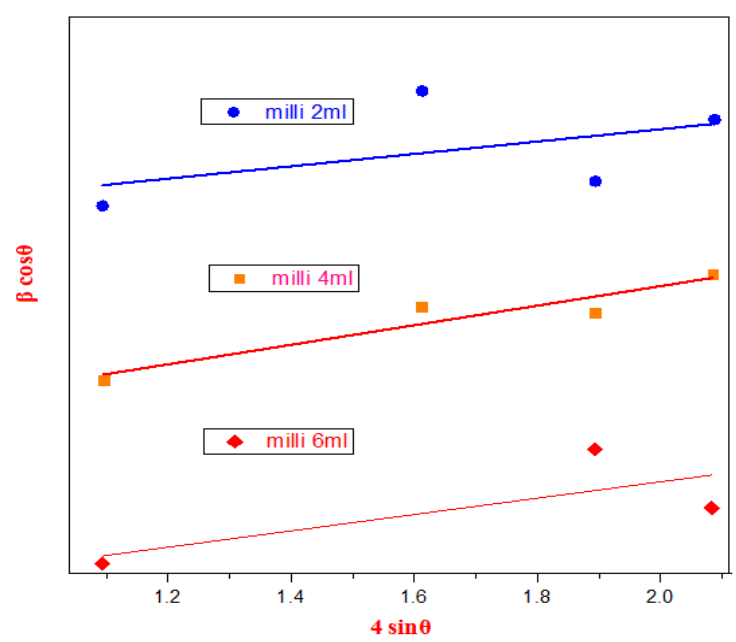

Figure 2: The $\mathrm{W}-\mathrm{H}$ analysis (UDM plot) of $\mathrm{ZnO}$ nanoparticles using Euphorbia milli as fuel 


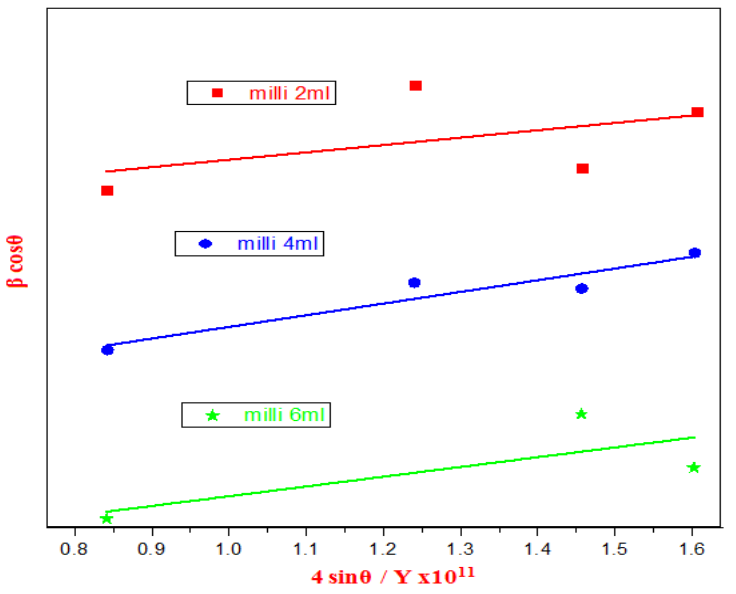

Figure 3: The $\mathrm{W}-\mathrm{H}$ analysis (USDM plot) of $\mathrm{ZnO}$ nanoparticles using Euphorbia milli as fuel

The graph of $\beta \cos \theta$ versus $4 \sin \theta /(\mathrm{Y} / 2)^{1 / 2}$ (where $\mathrm{Y}=$ $130 \times 10^{9} \mathrm{Nm}^{-2}$ ) was plotted. The plot obtained is shown in Figure 4. Using the intercept and slope particle size and energy density were calculated. micro strain $\varepsilon=(2 \mathrm{u} / \mathrm{Y})^{1 / 2}$ and stress $\zeta=\varepsilon \mathrm{Y}$ were also calculated. UDEDM analysis results are shown in Table 2. From the table2 we can conclude that as the particle size decreases, strain increases and energy density increases.

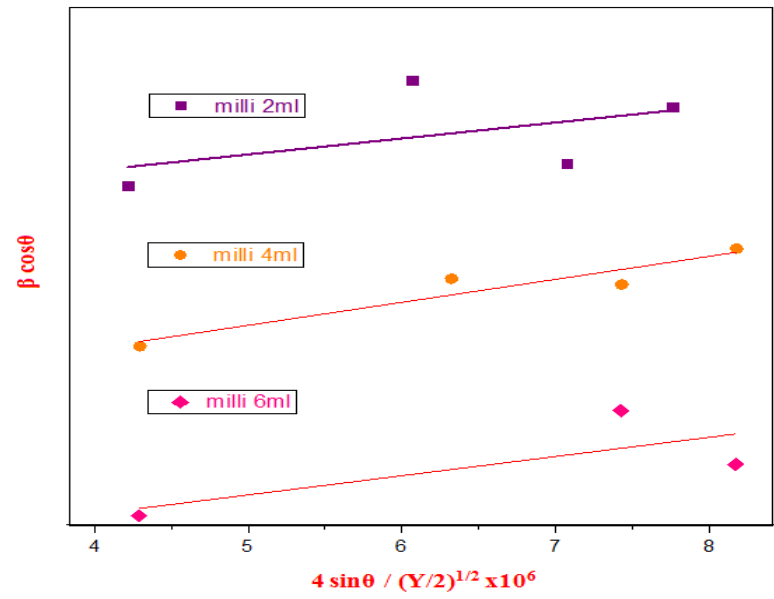

Figure 4: The $\mathrm{W}-\mathrm{H}$ analysis (UDEDM plot) of $\mathrm{ZnO}$ nanoparticles using Euphorbia milli as fuel

Figure.5 shows the FTIR spectra of ZnO NPs taken in the range $\left(400-4500 \mathrm{~cm}^{-1}\right)$. The FTIR peak at $3436 \mathrm{~cm}^{-1}$ represented $\mathrm{O}-\mathrm{H}$ group stretching of $\mathrm{O}-\mathrm{H}, \mathrm{H}$-bonded single bridge. The broad peak in the range of 3900 to $3800 \mathrm{~cm}^{-1}$ is attributed to water molecule present in thin films. The transmittance band at $435 \mathrm{~cm}^{-1}$ correspond to the $\mathrm{ZnO}$ bonding and confirm the formation of $\mathrm{ZnO}$ particles.

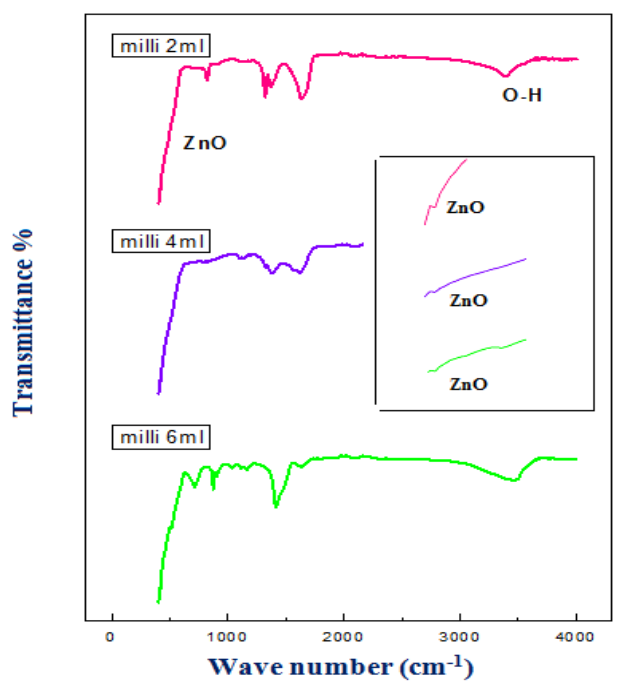

Figure 5: FTIR of $\mathrm{ZnO}$ with E. milli as latex

Fig 6 shows the optical absorption spectrum of ZnO NPs synthesized by using latex of E.milli. The sample has a clear and strongly observed absorption peak below at $400 \mathrm{~nm}$. The band gap energy corresponds to the absorption limit can be roughly evaluated by the relation $\mathrm{E}_{\mathrm{g}}=\mathrm{hC} / \lambda$ Where $\mathrm{E}_{\mathrm{g}}$ : band gap energy $(\mathrm{eV})$, h: Planck's constant $\left(6.625 \times 10^{-34} \mathrm{~J} \mathrm{~s}\right)$, $\mathrm{C}$ :velocity of light and $\lambda$ : wavelength $(\mathrm{nm})$ correspond to maximum absorption. From Fig 6 the absorption edge are positioned at $360 \mathrm{~nm}$ which corresponds to the band gap value of $3.44 \mathrm{eV}$.

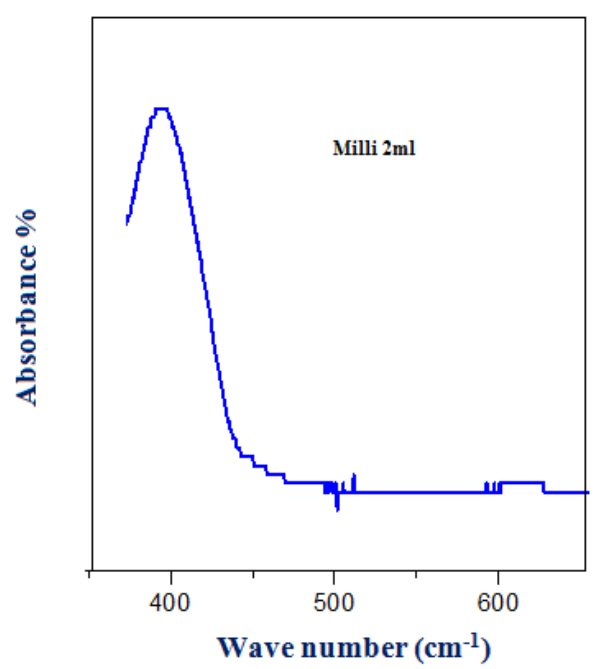

Figure 6: UV Visible spectra of $\mathrm{ZnO}$ using E.milli latex as fuel

Fig 7 shows the SEM micro graphs of as prepared ZnO NPs. It is observed that the particles were almost spherical in nature. Further, the particles are agglomerated to form foam like bunch of particles. The agglomeration could be induced by densification resulting in the narrow space between particles. When gas is escaping with high pressure, pores are formed with the simultaneous formation of small particles. The morphology of the powders reflects the inherent nature of the combustion process. The observations of the SEM studies crystallite size determination calculations were supported by TEM analysis.EDS and the table shows weight and atomicity of $\mathrm{Zn}$ and $\mathrm{O}$ in $\mathrm{ZnO}$ sample. 

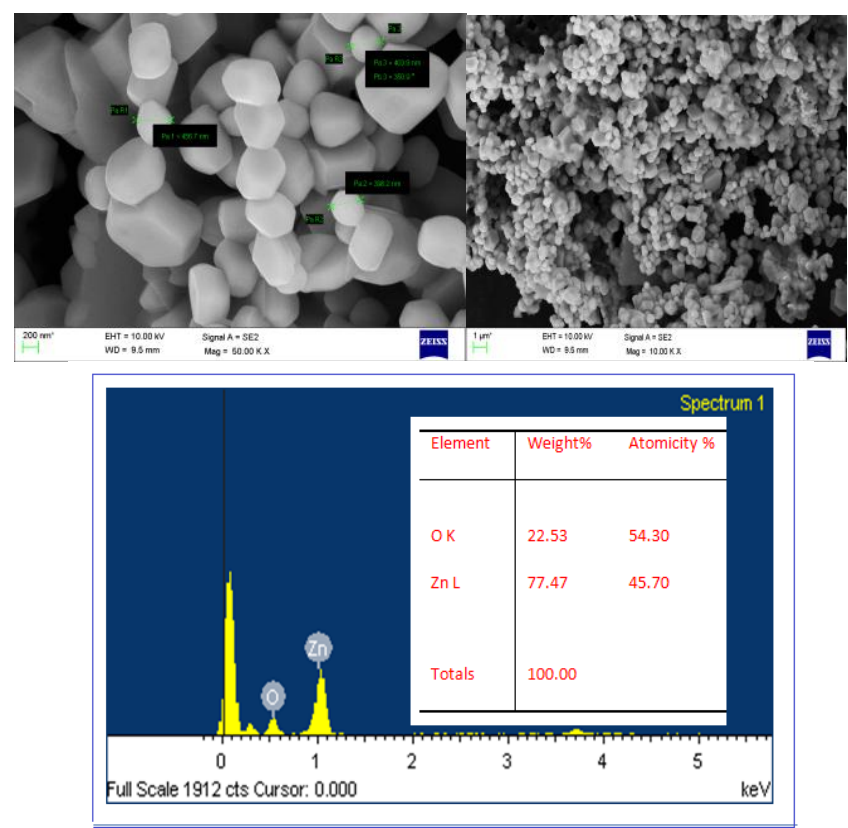

Figure 7: SEM images and EDS of $\mathrm{ZnO}$ nanoparticles.

The TEM images of $\mathrm{ZnO}$ are shown in Fig.8 respectively. The TEM study was carried out to understand the crystalline characteristics and size of the nanoparticles. The images TEM of $\mathrm{ZnO}$ confirm that the particles are almost spherical with non uniform thickness. The average particle size by histogram was found to be $50 \mathrm{~nm}$ to $200 \mathrm{~nm}$. This image reveals that most of the $\mathrm{ZnO}$ NPs are quasi-spherical and their diameter is about $50 \mathrm{~nm}$. The SAED pattern revealed that the diffraction rings of the synthesized $\mathrm{ZnO}$ exhibited Debye-Scherrer rings assigned (100), (002), (101),(102), (110), (103), (200), (112), (201), (004) and (202) respectively. Lattice planes of the face centered cubic (fcc) $\mathrm{ZnO}$, indicating that the biogenic NPs seen in the TEM images are nano-crystalline in nature as shown in Fig 8c. The HRTEM shows the planes with inter-planar spacing of 3.128A. The particle size determined from TEM analysis is in good agreement with XRD analysis.
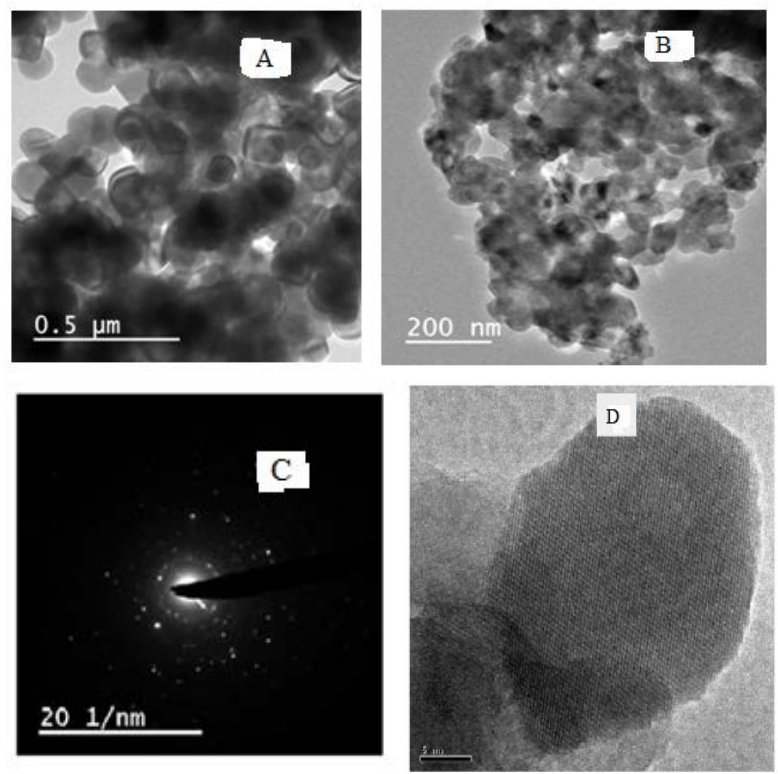

Figure 8: TEM images of ZnO NPs (A \& B), SAED pattern(C) and HRTEM (D) of ZnO .
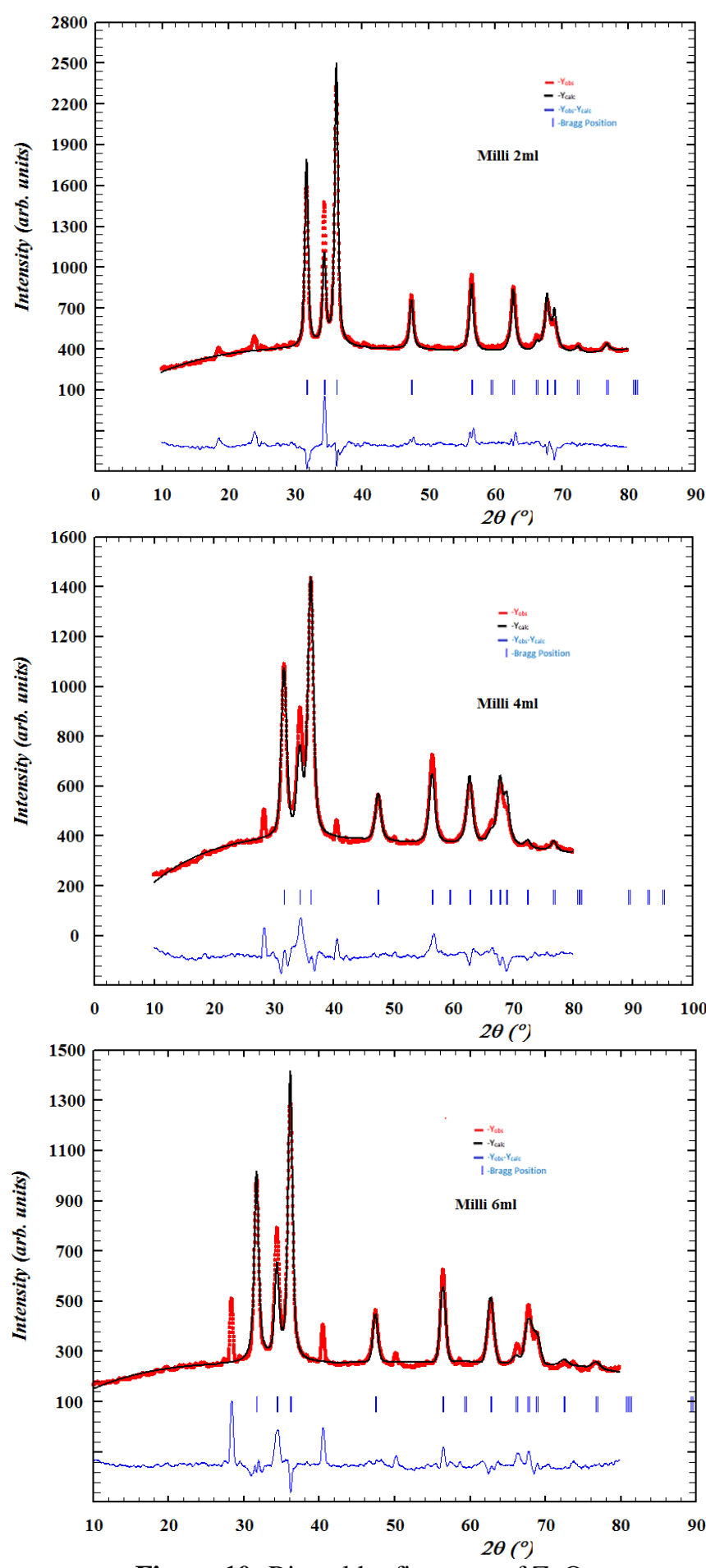

Figure 10: Rietveld refinement of $\mathrm{ZnO}$

Rietveld refinement was done using FullProf software. Pseudo-Voigt function was used in order to fit the several parameters to the data point. The refined parameters such as occupancy, atomic functional positions for $\mathrm{ZnO} \mathrm{NPs}$ at $2 \mathrm{ml}$, $4 \mathrm{ml}$ and $6 \mathrm{ml}$ latex of E.milli were summarized in Table 3. A good agreement was obtained between the experimental relative intensity (observed XRD intensities) and simulated intensity (calculated XRD intensities). Cell parameters and cell volume confirms hexagonal wurtzite structure of $\mathrm{ZnO}$. 


\section{International Journal of Science and Research (IJSR) \\ ISSN (Online): 2319-7064 \\ Index Copernicus Value (2013): 6.14 | Impact Factor (2015): 6.391}

\section{Conclusions}

ZnO NPs were synthesized by combustion method using E.milli latex as reducing agent. From XRD, particle size were $11 \mathrm{~nm}, 5 \mathrm{~nm}$ and $3 \mathrm{~nm}$. This result was also supported by SEM and TEM results. FTIR spectra showed characteristic spectra of $\mathrm{ZnO}$ at $435 \mathrm{~cm}^{-1}$. From UV Visible spectra energy gap was found to be $3.44 \mathrm{eV}$. SEM and TEM micro graphs shows that the particles are spherical in shape. The HRTEM of this method shows the planes with inter-planar spacing of $3.128 \mathrm{~A}^{\circ}$. GOF (goodness of fit) by Rietveld refinement is 1.2 , which shows good agreement between theoretical and experimental values. Advantages of this method is that it is eco friendly, fast, convenient and $\mathrm{ZnO}$ can be used for suitable applications like gas sensing, catalyst, for semiconductors, UV-shielding materials, nano generators, an antibacterial agent, cosmetics as well as medicinal applications.

\section{References}

[1] C.R. Martin, Science 266 (1994) 1961-1966.

[2] V. R. Shinde, T. P. Gujar, C. D. Lokhande, R. S. Mane, and S. H. Han, Mater. Chem. Phys. Vol 96, 2006, pp 326-330.

[3] S. Y. Yang, A. B. Pakhomov, S. T. Hund, and C. Y. Wong, IEEE Trans. Magn. Vol 38, 2002, pp 2877 2879.

[4] Y.I. Alivov, E.V. Kalinina, A.E. Cherenkov, D.C. Look, B.M. Ataev, A.K. Omaev,M.V. Chuki Chev, D.M. Bagnall, Appl. Phys. Lett. 83 (2003) 4719-4721.

[5] D. Calestani, M.Z. Zha, R. Mosca, A. Zappettini, M.C. Carotta, V. Di Natale, L.Zanotti, Sens. Actuat. B Chem. 144 (2010) 472-478.

[6] L.L. Xia, T.Q. Xin, S.C. Lu, L.Y. Chun, Chin. Phys. Let. 22 (2005) 998-1001.

[7] C. Suresh, J.M. Kelly, R. Ramesh, D.E. Mc, J. Mater. Chem. C 1 (2013) 3268-3281.

[8] Z.L. Wang, J. Phys. Condens. Matter 16 (2004) R829R858.

[9] A. Yu, J. Qian, H. Pan, Y. Cui, M. Xu, L. Tu, Q. Chai, X. Zhou,Sensors Actuators B Chem. 158 (2011) 9-16.

[10] R. Li, S. Yabe, M. Yamashita, S. Momose, S. Yoshida, S. Yin,T. Sato, Solid State Ionics 151 (2002) 35-241.

[11] M.P. Lu, J. Song, M.Y. Lu, M.T. Chen, Y. Gao, L.J. Chen,Z.L. Wang, Nano Lett. 9 (2009) 1223-1227.

[12] Ling Chuo Ann, Shahrom Mahmud, Siti Khadijah Mohd Bakhori, Amna Sirelkhatim, Dasmawati Mohamad, Habsah Hasan, Azman Seeni, Rosliza Abdul Rahman, Ceram. Int. 40 (2014) 2993-3001.

[13] R. Salehi, M. Arami, N.M. Mahmoodi, H. Bahrami, S. Khorramfar, Colloids Surfaces B 80 (2010) 86-93.

[14] Davood Raoufi, Renew. Energy 50 (2013) 932e937.

[15] J. Ma, J. Liu, Y. Bao, Z. Zhu, X. Wang, J. Zhang, Ceram. Int.39 (2013) 2803-2810.

[16] K.S. Sumana, B.M. Nagabhushana, C. Shivakumara, M. Krishna, Chandrasekhara Murthy, N. Raghavendra, Int. J. Sci. Res. 1 (2012) 83-86.
[17]S. Suwanboon, Structural and optical properties of nanocrystalline $\mathrm{ZnO}$ powder from sol-gel method, Sci. Asia 34(2008) 31-34.

[18] L.V. Podrezora, S. Porro, V. Cauda, M. Fontana, G. Cicero, Comparison between $\mathrm{ZnO}$ nanowires grown between chemical vapor deposition and hydrothermal synthesis, App. Phys. A 113(2013) 623-632.

[19] R. Ayouchi, F. Martin, D. Leinen, J.R. Ramos-Morrado, Growth of pure $\mathrm{ZnO}$ thin films prepared by chemical spray pyrolysis on silicon, J. Cryst. Growth 247 (2013) 497-504.

[20] A. Khorsand Zak, W.H. Abd Majid, H.Z. Wang, Ramin Yousefi, A. Moradi Golsheikh, Z.F. Ren, Sonochemical synthesis of hierarchical $\mathrm{ZnO}$ nanostructures, Ultrason. Sonochem 2 (2013) 395-400.

[21] K.C. Patil, S.C. Aruna, M. Mimani, Combustion synthesis: an update, Curr. Opin. Solid State Mater. Sci. 6 (2002) 507-512.

[22] K.C. Patil, M.S. Hegde, Tanu Rattan, S.T. Aruna, Chemistry of Nanocrystalline Oxide Materials, World Scientific, New Jersey,2008.

[23] M. Chandrasekhar, H. Nagabhushana, S.C. Sharma, K.H. Sudheer Kumar, N. Dhananjaya, D.V. Sunitha, C. Shivakumara, B.M. Nagabhushana, J. Alloy. Compd. 584 (2014) 417

[24] D. Kavyashree , R.AnandaKumari , H.Nagabhushana , S.C.Sharma , Y.S.Vidya , K.S. Anantharajuf, B.DarukaPrasad , S.C.Prashantha , K.Lingarajuh, H.Rajanaik Journal ofLuminescence167(2015)91-100

[25]D. Suresh , Udayabhanu , P.C. Nethravathi , K. Lingaraju , H. Rajanaika , S.C. Sharma ,H. Nagabhushana, Spectrochimica Acta Part A: Molecular and Biomolecular Spectroscopy 136 (2015) 1467-1474

\section{Authors Profile.}

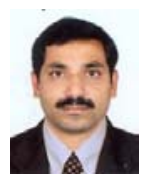

Dr. H. Nagabhushana is the Chairman and Associate Professor of the Department of Studies and Research in Physics at Tumkur University, India. He received his Ph. D degree from Bangalore University and D. Sc. from Tumkur University India. His main research interests are: preparation of nano phosphors, nano catalysts, nano sensors, nano pigments, solid oxide fuel cell electrode materials, nano ceramics, bio ceramics, nano metal oxides, by combustion synthesis, hydrothermal, sol-gel, solid state, solvothermal, etc. Study of Luminescence (Iono, Photo, Thermo) properties of nano materials and minerals.

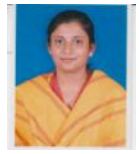

Mrs. M. S. Geetha is lecturer in Vijaya Composite College, Bangalore, India. She is pursuing Ph.D in Tumkur University, India. She has cleared NET (UGCCSIR) with distinction (All India Rank-09). Her research interest is mainly green synthesis, characterization and applications of nanomaterials.

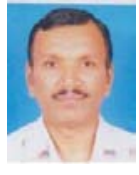

Mr. H. N. Shivananjaiah is an Associate Professor in Government Science College, Bangalore, India. He received his $\mathrm{M}$. Sc degree in inorganic chemistry from Bangalore University, India. His research interest is chemical synthesis, characterization and applications of nano oxides. 
International Journal of Science and Research (IJSR)
ISSN (Online): 2319-7064
Index Copernicus Value (2013): 6.14 | Impact Factor (2015): 6.391

Table 2: Crystallite size, strain, stress and energy density of ZnO by WH plots.

\begin{tabular}{|c|c|c|c|c|c|c|c|c|c|}
\hline sample & \multicolumn{2}{|c}{$U D M$} & \multicolumn{4}{|c|}{$U S D M$} & \multicolumn{4}{c|}{$U D E D M$} \\
\hline & $D(\mathrm{~nm})$ & $\epsilon X 10^{-3}$ & $D(\mathrm{~nm})$ & $\epsilon X 10^{-3}$ & $\zeta(M \mathrm{~Pa})$ & $D(\mathrm{~nm})$ & $\epsilon X 10^{-3}$ & $\zeta(\mathrm{MPa})$ & $U\left(\mathrm{kJm}^{-3}\right)$ \\
\hline $2 \mathrm{ml}$ & 11 & 14.03 & 11 & 14.07 & 1830 & 11 & 14.04 & 1825.2 & 12816 \\
\hline $4 \mathrm{ml}$ & 7.4 & 18.57 & 7.4 & 18.79 & 2443 & 7.4 & 18.55 & 2441.4 & 22944 \\
\hline $6 \mathrm{ml}$ & 5 & 18.79 & 5 & 18.56 & 2414 & 5 & 18.55 & 2411.5 & 22372 \\
\hline
\end{tabular}

Table 3 Crystal parameters of $\mathrm{ZnO}$ by Rietveld refinement

\begin{tabular}{|c|c|c|c|}
\hline & Milli $2 \mathrm{ml}$ & Milli 4ml & Milli $6 m l$ \\
\hline Crystal system & Hexagonal & Hexagonal & Hexagonal \\
\hline Laue class & $6 / \mathrm{m}$ & $6 / \mathrm{m}$ & $6 / \mathrm{m}$ \\
\hline Point group & 6 & 6 & 6 \\
\hline Bravis lattice & $\mathrm{P}$ & $\mathrm{P}$ & $\mathrm{P}$ \\
\hline Lattice symbol & $\mathrm{hP}$ & $\mathrm{hP}$ & $\mathrm{hP}$ \\
\hline \multicolumn{4}{|l|}{ Cell parameters } \\
\hline$a=b$ & 3.2595 & 3.2595 & 3.2617 \\
\hline$c$ & 5.221 & 5.221 & 5.216076 \\
\hline$\alpha=\beta$ & 90 & 90 & 90 \\
\hline$\gamma$ & 120 & 120 & 120 \\
\hline Direct cell volume $\left(A^{\circ}\right)^{3}$ & 48.041 & 48.041 & 48.0594 \\
\hline \multicolumn{4}{|l|}{ Atomic coordinates } \\
\hline \multicolumn{4}{|l|}{$\mathrm{Zn}$} \\
\hline$x$ & 0.3333 & 0.3333 & 0.3333 \\
\hline$y$ & 0.6666 & 0.6666 & 0.6666 \\
\hline$Z$ & 0.0362 & 0.0362 & 0.0362 \\
\hline$B$ & 2.32496 & 2.32492 & 11.91064 \\
\hline Occupancy & 0.80144 & 0.80144 & 0.53234 \\
\hline \multicolumn{4}{|l|}{$O$} \\
\hline$x$ & 0.3333 & 0.3333 & 0.3333 \\
\hline$y$ & 0.6666 & 0.6666 & 0.6666 \\
\hline$Z$ & 0.3838 & 0.3838 & 0.3838 \\
\hline$B$ & 23.78005 & 23.78005 & 22.4229 \\
\hline Occupancy & 2.46826 & 2.4682 & 1.14675 \\
\hline$R_{p}$ & 21 & 20.5 & 29.2 \\
\hline$R_{w p}$ & 19.1 & 18.5 & 26.2 \\
\hline$R_{\text {exp }}$ & 15.42 & 18.32 & 19.79 \\
\hline$R_{\text {braq }}$ & 4.01 & 3.37 & 4.68 \\
\hline$R_{F}$ & 5.74 & 4.88 & 7.73 \\
\hline$\chi^{2}$ & 1.54 & 1.02 & 1.75 \\
\hline GOF index & 1.2 & 1 & 1.3 \\
\hline Density of compound $(\mathrm{g} / \mathrm{cc})$ & 7.926 & 7.926 & 6.9 \\
\hline
\end{tabular}

Volume 5 Issue 4, April 2016 www.ijsr.net 